\title{
Molecular Imaging for Depressive Disorders
}

\author{
T.-S. Lee, S.Y. Quek, and K.R.R. Krishnan
}

\begin{abstract}
SUMMARY: Molecular imaging is the visualization, characterization, and measurement of biologic processes at the molecular and cellular levels in humans and other living systems. Molecular imaging techniques such as MR spectroscopy and PET have been used to explore the molecular pathophysiology of depression and assess treatment responses. MR spectroscopy is a noninvasive technique that assesses the levels of biochemical metabolites in the brain, while PET uses radioligands injected in the bloodstream that have high binding affinity for target molecules. MR spectroscopy findings suggest a role for glutamate/glutamine and gamma-aminobutyric acid in depression. PET has generally failed to find a correlation between radioligand binding potential and depression severity or treatment response, though it may offer promise in distinguishing responders and nonresponders to treatment. A major challenge for both modalities is that depression is a heterogeneous, multifactorial disorder, while MR spectroscopy and PET are limited to examining a few metabolites or a single radioligand at a time. This difference makes a comprehensive evaluation of neurochemical changes in the brain difficult.
\end{abstract}

ABBREVIATIONS: GABA = gamma-aminobutyric acid; Gln = glutamine; Glu = glutamate; 5 -HT = serotonin; $\mathrm{MDD}=$ major depressive disorder; $\mathrm{PCr}=$ phosphocreatinine

I he standard definition of molecular imaging, as provided by the Molecular Imaging Center for Excellence Standard Definitions Task Force, is the visualization, characterization, and measurement of biologic processes at the molecular and cellular levels in humans and other living systems. ${ }^{1}$ In this way, molecular imaging may offer further insights into the molecular pathology of various diseases in animal models and human subjects, aid in the development of molecular-targeted drugs, and potentially individualize established therapy regimens in clinical practice.

Molecular imaging requires probes that can bind to the target molecule with high affinity. Such probes may be radiopharmaceuticals or paramagnetic or fluorescent materials; small molecules such as receptor ligands or enzyme substrates; or higher molecular-weight-affinity ligands such as recombinant proteins. ${ }^{2}$ Another emerging application in molecular imaging is in the use of reporter genes. These genes can be used to visualize the levels of expression of specific endogenous and exogenous genes, as well as

Received October 2, 2013; accepted after revision February 26, 2014.

From the Duke-National University of Singapore Graduate Medical School, Singapore.

Please address correspondence to Tih-Shih Lee, MD, Duke-National University of Singapore Graduate Medical School Singapore, 8 College Rd, Singapore 169857; e-mail: tihshih.lee@duke-nus.edu.sg

- Indicates open access to non-subscribers at www.ajnr.org

http://dx.doi.org/10.3174/ajnr.A3965

other intracellular biologic phenomena such as signal transduction pathways and protein-protein interactions. ${ }^{3}$

Molecular imaging is performed with tools that enable signals from probes to be visualized and quantified in space and with time and includes techniques such as optical imaging, radiotracer imaging, sonography, MR spectroscopy, and PET. In the present article, we will focus on the use of MR spectroscopy and PET in the examination of depression.

\section{Major Depressive Disorder}

Major depressive disorder (MDD) is a great source of morbidity and suffering worldwide. In the United States, the 12-month prevalence is $6.6 \%$ and the lifetime prevalence is $16.2 \%{ }^{4}$ According to the Diagnostic and Statistical Manual of Mental Disorders (DSM-5), ${ }^{5}$ the diagnosis of MDD is made when 5 of 9 core symptoms are present for $>2$ weeks and indicate a change from a previous level of functioning. These core symptoms in MDD are the following: depressed mood; diminished interests; appetite changes leading to weight gain or loss; sleep dysregulation; psychomotor changes; loss of energy; feelings of worthlessness and excessive guilt; diminished concentration; and recurrent thoughts of death. These symptoms should not be attributable to the physiologic effects of a medical condition or substance misuse. The diagnostic criteria for MDD are largely unchanged from the DSM-IV Text Revision, ${ }^{6}$ and this similarity allows comparisons of current and future research studies with those that were previ- 
ously conducted. Now, a diagnosis of depression is made on the basis of clinical judgment. As of yet, there are no definitive blood/ CSF biomarkers or neuroimaging findings that can aid the clinician in making the diagnosis. However, blood, CSF, and urine analyses and brain scans may be ordered by the clinician to exclude a medical condition or substance misuse that may have led to the depressive symptoms.

\section{Molecular Neurobiology of Depression}

The neurobiologic basis for depression has not yet been definitively characterized. Existing theories involve alterations of neurotransmitter systems and networks in limbic and cortical brain regions. Early hypotheses involve the monoamines serotonin (5HT), norepinephrine, and dopamine; more recently, the involvement of glutamate (Glu) and gamma-aminobutyric acid (GABA) has also been proposed. Other neuropeptides involved in the pathophysiology of depression and that may have a role in treatment include corticotrophin-releasing factor, neuropeptide $\mathrm{Y}$, neurokinin/substance $\mathrm{P}$, and galanin. ${ }^{7}$

The accepted early dogma in the pathophysiology of depression involved a reduction in monoamines 5-HT and norepinephrine and, to a lesser extent, dopamine. Early findings that reserpine, an antihypertensive that depletes vesicular monoamine stores, led to depressive symptoms suggested a role of monoamines, especially catecholamines. Drugs that selectively inhibited the reuptake of 5-HT and norepinephrine and hence increased the intrasynaptic levels of these neurotransmitters were shown to be effective antidepressants. ${ }^{8}$ However, direct analysis of monoamine levels has been mixed, with some reports of reduced levels of 5-HT and norepinephrine in blood, CSF, and postmortem brain tissue. ${ }^{9,10}$ Currently, why, while the reuptake inhibitory effects of antidepressants occur within hours and days, the symptomatic improvement takes weeks remains an unresolved and vexing issue. Hence, other mechanisms are likely in play. ${ }^{11}$

In recent years, the focus has shifted away from monoamines to the amino acid neurotransmitters Glu and GABA. ${ }^{12}$ GABA is the major inhibitory neurotransmitter in the brain and counterbalances Glu, the major excitatory neurotransmitter. The balance of Glu and GABA is essential for normal brain function. GABA deficiency has been proposed as a model for anxiety and depression. In a series of studies, plasma GABA levels were lower in subjects with depression. ${ }^{13}$ Patients show a cortical GABA deficit, which is reversed by chronic selective serotonin reuptake inhibitor treatment. ${ }^{14}$ Moreover a partial GABA(A) receptor deficit is causal for depression-like behavior in animals and is reversed by chronic antidepressant treatment. ${ }^{15}$ Other evidence comes from postmortem studies that show a loss of GABAergic interneurons in the dorsal lateral prefrontal cortex of subjects with depression ${ }^{16}$ and a decrease in the glutamic acid decarboxylase. ${ }^{17}$ As with GABA, there is some evidence that the glutaminergic system, especially abnormalities of Glu and $N$-methyl-D-aspartate receptors, contributes to the pathophysiology of depression. ${ }^{18-20} \mathrm{~N}$ methyl-D-aspartate receptor antagonists have demonstrated antidepressant-like activity in preclinical and clinical studies. It has been postulated that glutamatergic receptor modulation may facilitate neuronal stem cell enhancement (neurogenesis) and release of neurotransmitters associated with treatment response.
From an anatomic point of view, the prefrontal cortex and limbic structures, such as the anterior cingulate cortex, have been implicated in the exaggerated response of a sense of guilt and despair to negative emotions. On the other hand, alterations in the hypothalamus and parts of the brain stem have been proposed as responsible for neurovegetative symptoms (eg, sleep and appetite dysfunction and fatigue). ${ }^{21}$ This may constitute the interface with the hypothalamus-pituitary axis. Hypothalamus-pituitary axis hyperactivity is also associated with depression, and this is manifested by increased plasma concentrations of cortisol and nonsuppression of adrenocorticotropic hormone and cortisol in the classic dexamethasone suppression test.

\section{Impact of Oxidative Stress in Depression}

Oxidative stress occurs when redox homeostasis is tipped toward an excess of free radicals, either due to their overproduction or deficiencies in antioxidant defenses. ${ }^{22}$ While oxygen is essential for aerobic functioning, excessive amounts of its free radical metabolic by-products are toxic. In high concentrations, free radicals can lead to the damage of cellular proteins, lipids, carbohydrates, and nucleic acids, which consequently may result in apoptosis and cell death. ${ }^{23}$

A growing body of research supports the involvement of oxidative stress in the pathophysiology of depression. A recent metaanalysis observed a significant association between depression and oxidative stress across studies. ${ }^{24}$ Markers of oxidative stress have been found to be higher in patients with major depression relative to controls, ${ }^{25,26}$ including in a postmortem study. ${ }^{27}$ Evidence for the impact of antidepressant treatment on oxidative stress, however, has been mixed, with some studies finding a decrease in oxidative stress after antidepressant treatment ${ }^{28}$ and others finding no such change. ${ }^{26,29}$

\section{Neuroimaging Application for Depression Research}

Neuroimaging is not routinely used for clinical diagnosis of depressive disorders. However, it may be used for excluding a neurologic lesion (eg, stroke, tumor, or atrophy that may physiologically contribute to mood dysregulation). Nevertheless, neuroimaging tools have been used to study the underlying biology and brain circuits that are relevant to the onset of depression, course of disease, and response to treatment. Volumetric studies have shown gray matter loss and volumetric reductions in subregions of the prefrontal cortex, medial temporal lobe, amygdala, and hippocampus across all age ranges. ${ }^{30,31}$ Hippocampal volume loss may be due to hyperactivity of the hypothalamus-pituitary axis, which leads to increased circulating glucocorticoids. ${ }^{32}$ Functional imaging, which is not covered in this review, has been used to show the activation in the corticolimbic mood-regulating circuit. $^{33}$

\section{Role of Molecular Imaging for Depression}

The living brains of humans can now be studied at a molecular level by neuroimaging tools such as MR spectroscopy and PET. While not used for clinical diagnosis, molecular imaging has a role to play in characterizing the molecular pathophysiology of the disease, studying putative new treatments in proof-of-concept trials, and assessing treatment response. Molecular imaging meth- 
Table 1: Summary of metabolites/compounds detected by each type of MRS and findings

\begin{tabular}{|c|c|c|}
\hline Type of MRS & Metabolites/Compounds Detected & Summary of Findings \\
\hline${ }^{19} \mathrm{~F}$ MRS & $\begin{array}{l}\text { Fluorine } 19 \text { nucleus } \\
\text { Fluorinated drugs (including SSRIs) }\end{array}$ & Used to study pharmacokinetics of fluoxetine and fluvoxamine ${ }^{31}$ \\
\hline${ }^{31} \mathrm{P}$ MRS & $\begin{array}{l}\text { Phosphomonoesters } \\
\text { Phosphodiesters } \\
\text { Inorganic phosphate } \\
\text { Phosphocreatine } \\
\alpha-, \beta-\text {, and } \gamma \text {-nucleoside triphosphate }\end{array}$ & $\begin{array}{l}\text { Membrane phospholipid and energy metabolism abnormalities in frontal } \\
\text { and temporal lobes of patients with bipolar disorder }{ }^{36} \\
\text { Lower phosphomonoester levels for patients with euthymic } \\
\text { bipolar disorder } \\
\text { Increased phosphomonoester and decreased ATP levels in frontal } \\
\text { lobes of unipolar depressed patients }{ }^{38}\end{array}$ \\
\hline Proton MRS & $\begin{array}{l}\text { Glx } \\
\text { GABA } \\
\text { NAA } \\
\text { Cr+PCr } \\
\text { Cho } \\
\text { mlns }\end{array}$ & See Table 2 \\
\hline
\end{tabular}

Note:-APT indicates adenosine triphosphate; SSRI, selective serotonin reuptake inhibitor.

ods were initially used to test the hypothesis of decreasing monoaminergic function, in particular serotonin, in depression. Given the rapid advances in imaging technologies and radiotracer chemistry, any review will likely be supplanted shortly after publication. Hence, we will simply summarize the findings to date.

\section{MR Spectroscopy}

MR spectroscopy is a noninvasive technique that can provide a quantitative measure of biochemical concentration in the living brain. It has high spatial resolution and requires neither radioactive tracers nor ionizing radiation. Different molecules have unique MR spectra, which can be quantified by taking the area under the signal curve and measuring it against the curve of a standard metabolite. Unlike MR imaging, which measures the signal from protons in water molecules (typically at concentrations of approximately $35 \mathrm{~mol} / \mathrm{L}^{34}$ ) to produce images, MR spectroscopy detects the signals from compounds in lower concentrations (typically at concentrations of $0.5-10 \mathrm{mmol} / \mathrm{L}$ ). ${ }^{35}$ These include ${ }^{1} \mathrm{H}$ (proton), phosphorus $31\left({ }^{31} \mathrm{P}\right)$, sodium 23 , lithium $7,{ }^{36}$ and fluorine $19\left({ }^{19} \mathrm{~F}\right) .{ }^{37} \mathrm{MR}$ spectroscopy has been used to understand the neurobiology of depression and to study its use in predicting treatment response. Table 1 offers a summary of metabolites and compounds detected by each type of MR spectroscopy and their key findings.

\section{Fluorine MR Spectroscopy}

${ }^{19} \mathrm{~F}$ MR spectroscopy has been of interest to researchers since the early days of MR spectroscopy because a large number of psychiatric medications contain the fluorine-19 nucleus, which is naturally abundant and has an MR spectroscopy sensitivity of $83 \%$ relative to protons. ${ }^{38}$ Fluorinated drugs include selective serotonin reuptake inhibitors such as fluoxetine and fluvoxamine, which are the most commonly prescribed antidepressants in the world today. ${ }^{19} \mathrm{~F}$ MR spectroscopy has been used in understanding the pharmacokinetics in target organs and in correlating brain concentrations of the selective serotonin reuptake inhibitors fluoxetine and fluvoxamine with clinical responses in patients with MDD, ${ }^{39}$ as well as in social phobia ${ }^{40}$ and in a pediatric population treated for pervasive developmental disorders. ${ }^{41}$ Fluorine levels in the brain are very high and are sustained for a long time, reflecting the accumulation of the drug in the brain, which explains the potential long duration of action of the drug. Recently, Wolters et $\mathrm{al}^{42}$ explored the possibility of using dual-targeted molecular imaging in the form of hybrid ${ }^{1} \mathrm{H} /{ }^{19} \mathrm{~F}$ imaging and spectroscopy for various clinical applications. Nevertheless, despite the potential utility of ${ }^{19} \mathrm{~F}$ MR spectroscopy for examining the mechanisms of antidepressants, the extant literature is scarce, and this remains an area worth exploring in future research.

\section{Phosphorus MR Spectroscopy}

Phosphorus MR spectroscopy can measure phosphate metabolism, providing important information about cellular energetics, membrane metabolism, and $\mathrm{pH}$. The common brain metabolites and molecules measured by ${ }^{31} \mathrm{P} \mathrm{MR}$ spectroscopy include phosphomonoesters; phosphodiesters; inorganic phosphate; phosphocreatine; and $\alpha$-, $\beta$-, and $\gamma$-nucleoside triphosphate. ${ }^{43}$

${ }^{31} \mathrm{P}$ MR spectroscopy has more often been used to examine bipolar disorders, though findings of some studies have been extended to MDD. ${ }^{31} \mathrm{P}$ MR spectroscopy studies have suggested membrane phospholipid and energy metabolism abnormalities in the frontal and temporal lobes of patients with bipolar disorders, ${ }^{44}$ with a meta-analysis finding significantly lower phosphomonoester levels in patients with euthymic bipolar disorders than in healthy controls and patients with depression having significantly higher phosphomonoester levels than those with euthymic bipolar disorders. ${ }^{45}$ This may suggest trait- and possible statedependent abnormalities of membrane phospholipid metabolism, which may indicate dysfunction in brain-signal transduction systems in bipolar and depressive disorders.

When one focuses on MDD alone, significantly increased phosphomonoester and decreased adenosine triphosphate levels have also been found in the frontal lobes of patients with unipolar depression compared with healthy controls. ${ }^{46}$ In a recent study on late-life depression, glycerophosphoethanolamine was found to be elevated in the white matter of subjects with depression, suggesting an enhanced degeneration of cell membranes in these subjects relative to healthy elderly. ${ }^{47}$ An important limitation of ${ }^{31} \mathrm{P} \mathrm{MR}$ spectroscopy, however, is the relatively low sensitivity of the method-approximately $5 \%$ of that of proton MR spectroscopy. ${ }^{48}$

\section{Proton MR Spectroscopy}

The proton is one of the most commonly studied nuclei in MR spectroscopy due to its high sensitivity and abundance in most metabo- 
lites. In addition, proton spectroscopy is easier to perform and provides much higher signal-to-noise ratios than either sodium or phosphorus. Proton MR spectroscopy can be performed within 10-15 minutes by using clinical MR imaging systems with standard radiofrequency coils developed for the acquisition of diagnostic MR images; in contrast, the standard MR imaging coils cannot be used when nuclei other than ${ }^{1} \mathrm{H}$ are studied, and special coils tuned to the desired nucleus have to be bought or built instead. ${ }^{35}$

Proton MR spectroscopy can reliably detect NAA, Cr+ phosphocreatine (PCr), Cho-containing compounds including phosphocholine and glycerophosphocholine, and myo-inositol in the brain. These brain metabolites measured by ${ }^{1} \mathrm{H}-\mathrm{MR}$ spectroscopy are involved in cellular metabolism, neurotransmission, and cell membrane synthesis, or they serve as a specific marker for neurons and glia. The $\mathrm{Cr}+\mathrm{PCr}$ level is relatively stable across the brain and is used as an internal concentration reference, with some caveats-for example, $\mathrm{Cr}+\mathrm{PCr}$ ratios may be distorted in cases of tumor and stroke. At higher field strengths, Glu and glutamine (Gln) and others can be resolved. Gln is the precursor and a product of Glu and then is metabolized to GABA. Glu in synapses is also rapidly removed and converted back to Gln. Glutamine is synthesized in astrocytes from Glu and then in neurons is converted back to Glu. Hence Glu and Gln are closely linked molecules.

NAA functions as an acetyl donor for acetyl coenzyme A and takes part in lipid synthesis, including myelin. Because it is localized only in neurons, it is a putative neuronal marker. Hence a reduction in NAA levels is indicative of neuronal loss and dysfunction. In the case of chronic depression, it may suggest a neurodegenerative process. Figure 1 shows an example of chemical shift imaging output of NAA for MR spectroscopy.

Cho is the precursor of neurotransmitter acetylcholine and membrane lipids, phosphatidylcholine and sphingomyelin, ${ }^{49}$ and is a marker for the state of membrane phospholipid metabolism. An elevated Cho signal, therefore, most likely reflects higher membrane turnover and damage to myelin or neurons. The Cho signal measures not just Cho but also the underlying phosphocholine and glycerophosphocholine.

Myo-inositol is traditionally considered a glial marker ${ }^{50}$ because it is actively transported into astrocytes ${ }^{51,52}$ and functions in osmoregulation in brain glial cells. ${ }^{53}$ Higher levels probably reflect gliosis.

Table 2 lists some important properties of and findings for the metabolites of interest described above, while Fig 2 shows proton MR spectroscopy identification for assignments of these compounds.

Comprehensive reviews and a major meta-analysis on MR spectroscopy for MDD and a review of MR spectroscopy for evaluation of treatment efficacy have been conducted by YildizYesiloglu and Ankerst, ${ }^{50}$ Rao et al, ${ }^{54}$ and Caverzasi et al, ${ }^{55}$ respectively, and interested readers can refer to these articles for more information on the extant literature. In this article, we present key findings and attempt to draw conclusions from the data available.

Despite the wide diversity of proton MR spectroscopy methods applied, brain regions studied, and molecules, there appears to be some evidence of a correlation between certain metabolite concentrations, in particular Glu, GABA and Cho, and a good treatment response to pharmacotherapy or stimulation techniques.

\section{Metabolites of Interest}

Glx. Studies have shown decreased Glx in the anterior cingulate cortex ${ }^{19,56,57}$ in patients with depression, and these levels improved with electroconvulsive therapy. ${ }^{19}$ Decreased levels of Glx have also been found in the amygdala-hippocampus of patients with depression. ${ }^{58}$ In contrast, Sanacora et $\mathrm{al}^{59}$ found elevated Glu in the occipital cortex. There is evidence, however, that Glu may be differentially involved in depression and bipolar disorder. In a review, Yüksel and Öngür ${ }^{60}$ found an overall reduction of Glx in depressive disorders in contrast to elevation in bipolar disorders. This finding may suggest that depressive and manic episodes are characterized by modulation of the Glx ratio in opposite directions.

GABA. Using MR spectroscopy, Sanacora et $\mathrm{al}^{61}$ found that patients with depression have significantly lower GABA concentrations in the occipital cortex relative to healthy controls. These findings were replicated in a subsequent study by the same authors ${ }^{59}$ by using a larger sample size. Patients who were most severely depressed and who had the lowest GABA concentrations showed the largest increase after selective serotonin-reuptakeinhibitor treatment. In contrast to findings of reduced GABA concentrations only in the occipital cortex, Hasler et $\mathrm{al}^{62}$ reported that GABA, Glu, and Gln were all reduced in the prefrontal cortex of subjects with depression. Bhagwagar et $\mathrm{al}^{63}$ also reported low GABA in the occipital and anterior cingulate cortices.

NAA or NAA/Cr. A meta-analysis showed no significant differences in NAA values between patients with depression and healthy subjects in both the basal ganglia and frontal lobe structures, ${ }^{50}$ though a few studies have found a decreased NAA/Cr ratio in the thalamus ${ }^{64}$ and decreased NAA in the caudate ${ }^{65}$ in patients with depression. The general lack of significant findings for NAA or NAA/Cr may suggest an increased membrane turnover in MDD without a neurodegenerative outcome.

Cho. Results were mixed, but in the meta-analysis of proton MR spectroscopy, Yildiz-Yesiloglu and Ankerst ${ }^{50}$ found that adult patients with MDD had higher Cho/Cr values in the basal ganglia compared with controls. Moreover, the Cho elevation reversed with antidepressant treatment.

Myo-inositol. Most studies reported negative findings in the anterior cingulate cortex and basal ganglia and mixed results for the prefrontal cortex. ${ }^{54}$

Proton MR spectroscopy has also been used to examine depression and the impact of antidepressants in animal models. The chronic mild stress model is well-documented as an animal model of depression. ${ }^{66}$ In rats, repeated exposure to mild stressors induced anhedonia- a core symptom of major depressive disorder. The most consistent finding emerging from animal studies is that NAA is significantly reduced in the hippocampi of both rat ${ }^{67,68}$ and tree shrew ${ }^{69}$ models subjected to chronic stress, with the administration of antidepressants escitalopram and tianeptine reversing these decreases to normal levels in the latter 2 studies, respectively. Similar to results from human depression studies, Hemanth Kumar et $\mathrm{al}^{67}$ also found a significant decrease of Glu, Gln, and GABA levels in the hippocampus and prefrontal cortex of rats with chronic mild stress. In contrast, Perrine et $\mathrm{al}^{70}$ found 
a significant increase in GABA levels in the anterior cingulate of stressed rats, with the administration of ketamine blunting depression-like behavior and increasing GABA levels in the anterior cingulate. However, the results of these studies are not directly

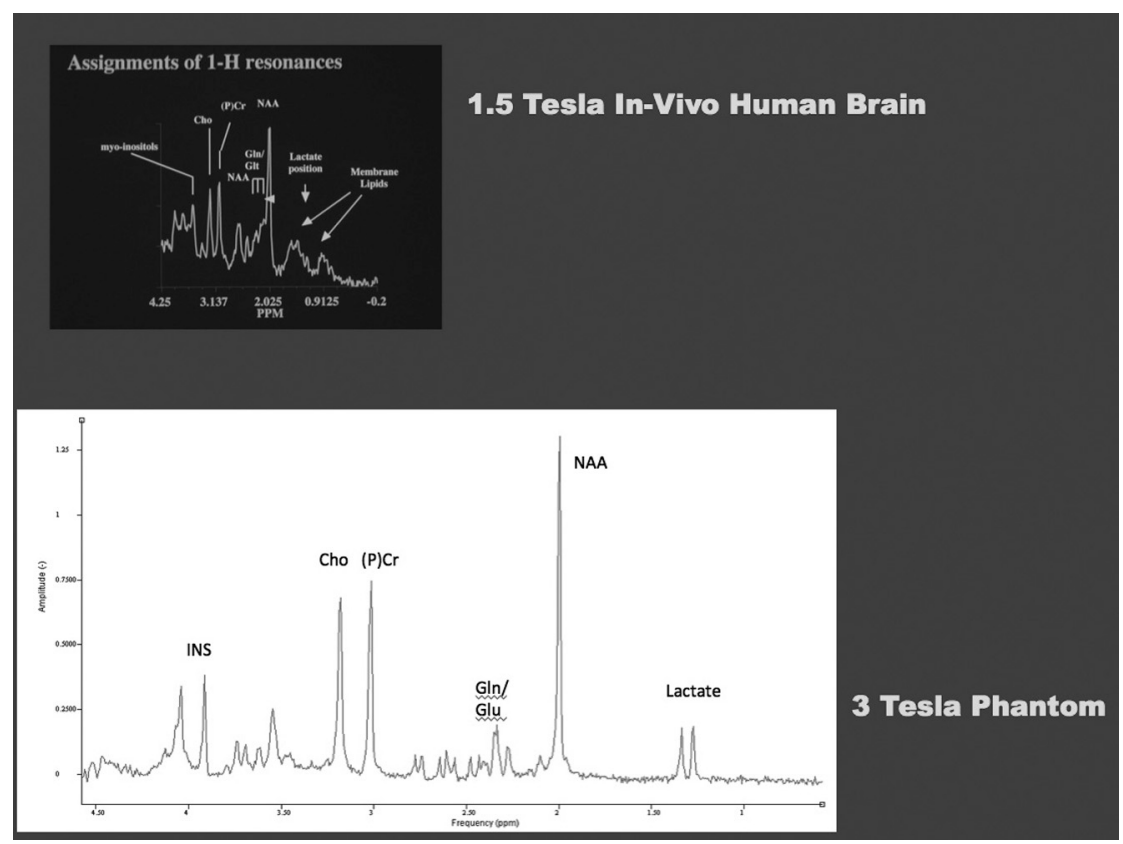

FIG 1. 2D chemical shift imaging of $N$-acetylaspartate. Courtesy of Cecil Charles, Duke University.

Table 2: Summary of metabolites detected by proton MRS and findings

\begin{tabular}{|c|c|c|}
\hline $\begin{array}{l}\text { Metabolite of } \\
\text { Interest }\end{array}$ & Key Properties & $\begin{array}{l}\text { Findings for Patients with } \\
\text { Depression Relative to Controls }\end{array}$ \\
\hline Glu/Glutamine & $\begin{array}{l}\text { Complex signal } \\
\text { Requires difference technique at intermediate field } \\
\text { strengths }\end{array}$ & $\begin{array}{l}\text { Decreased Glu/Gln in anterior cingulate }{ }^{19,56,57} \\
\text { Decreased Glu/Gln in amygdala-hippocampus } \\
\text { Decreased Glu/Gln in prefrontal cortex } \\
\text { Elevated Glu in occipital cortex } \\
\text { Reduction of Glx (mainly Glu and Gln) in depressive } \\
\quad \text { disorder but elevation in bipolar disorder } \\
\text { Response to treatment: increased levels with ECT }\end{array}$ \\
\hline GABA & $\begin{array}{l}\text { Complex signal } \\
\text { Requires different technique at } \\
\text { intermediate field strengths }\end{array}$ & $\begin{array}{l}\text { Decreased in occipital cortex } \\
\text { Decreased in occipital and anterior cingulate cortex } \\
\text { Decreased in prefrontal cortex } \\
\text { Re } \\
\text { Response to treatment: patients who were most severely } \\
\text { depressed and who had lowest GABA concentrations } \\
\text { showed largest increase after SSRI treatment }{ }^{59}\end{array}$ \\
\hline $\mathrm{NAA}$ or NAA/Cr & $\begin{array}{l}\text { Only present in neurons } \\
\text { Change reflects loss or decreased } \\
\text { function of neurons }\end{array}$ & $\begin{array}{l}\text { Decreased NAA/Cr in thalamus }{ }^{64} \\
\text { Decreased NAA in caudate }{ }^{65} \\
\text { Meta-analysis: no significant differences in NAA between } \\
\text { depressed and healthy subjects in basal ganglia } \\
\text { and frontal lobe structures }\end{array}$ \\
\hline $\mathrm{Cr}+\mathrm{PCr}$ & $\begin{array}{l}\text { Reflects tissue energetics } \\
\sim 7.8 \mu \mathrm{mol} / \mathrm{g}^{117}\end{array}$ & $\begin{array}{l}\text { No significant differences in } \mathrm{Cr} \text { levels in frontal } \\
\text { lobe structures between depressed } \\
\text { and healthy subjects }\end{array}$ \\
\hline Cho & $\begin{array}{l}\text { Concentration of pool: } \sim 2 \mu \mathrm{mol} / \mathrm{g}^{117} \\
\text { Reflects mobile Cho (TMA) moieties } \\
\text { Cho concentration rate limiting step in } \\
\text { acetylcholine synthesis } \\
\text { Dynamic equilibrium with acetylcholine } \\
\text { and phospholipid pathways }\end{array}$ & $\begin{array}{l}\text { Mixed findings } \\
\text { Meta-analysis: elevated in basal ganglia }{ }^{50} \\
\text { Response to treatment: choline elevation reverses with } \\
\quad \text { antidepressant treatment }{ }^{50}\end{array}$ \\
\hline mlns & $\begin{array}{l}\text { Diverse role in central nervous system } \\
\quad \text { (gliosis, cytoskeleton, cellular signaling) }\end{array}$ & $\begin{array}{l}\text { Generally negative findings in anterior cingulate cortex, } \\
\text { basal ganglia } \\
\text { Mixed results for prefrontal cortex }\end{array}$ \\
\hline
\end{tabular}

Note:-ECT indicates electroconvulsive therapy; SSRI, selective serotonin reuptake inhibitor; TMA, trimethylamine. 


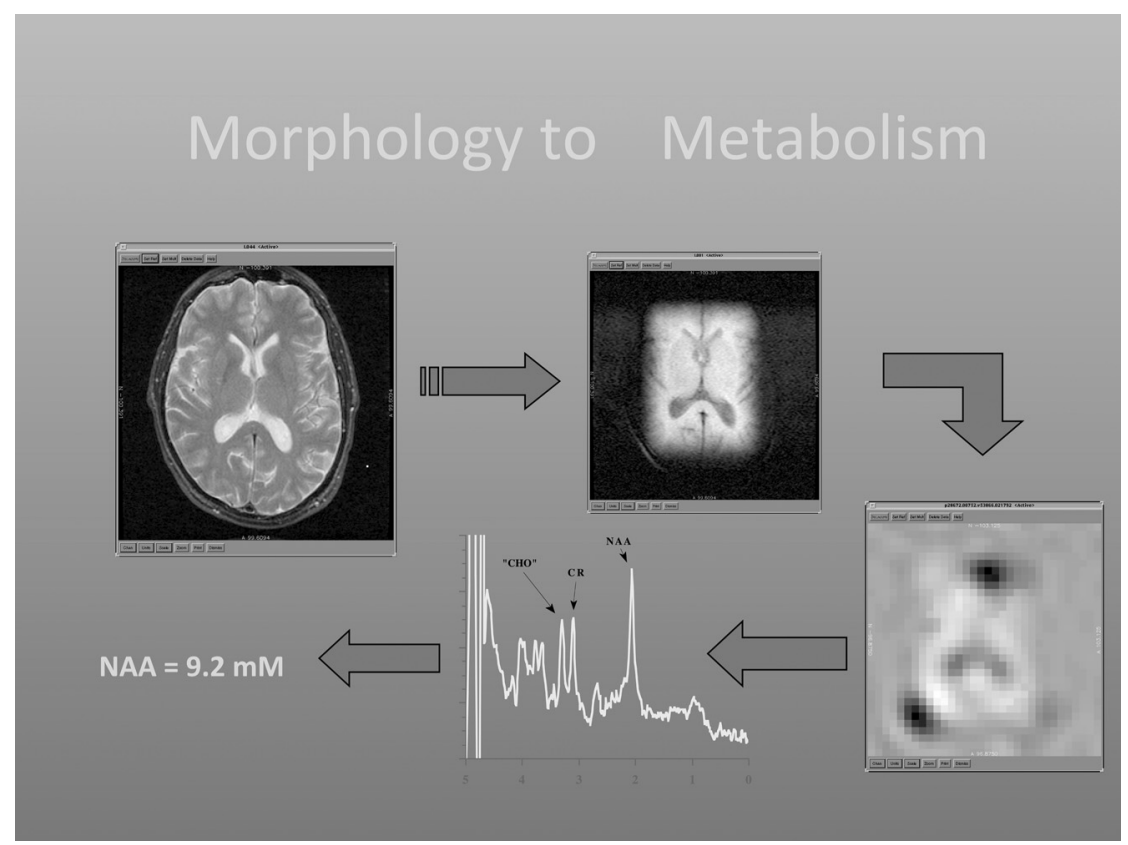

FIG 2. Proton MR spectroscopy identification of assignments of compounds. Courtesy of Cecil Charles, Duke University.

Table 3: Common neurotransmitter systems studied in PET imaging and radioligands used for each component or pathway involved

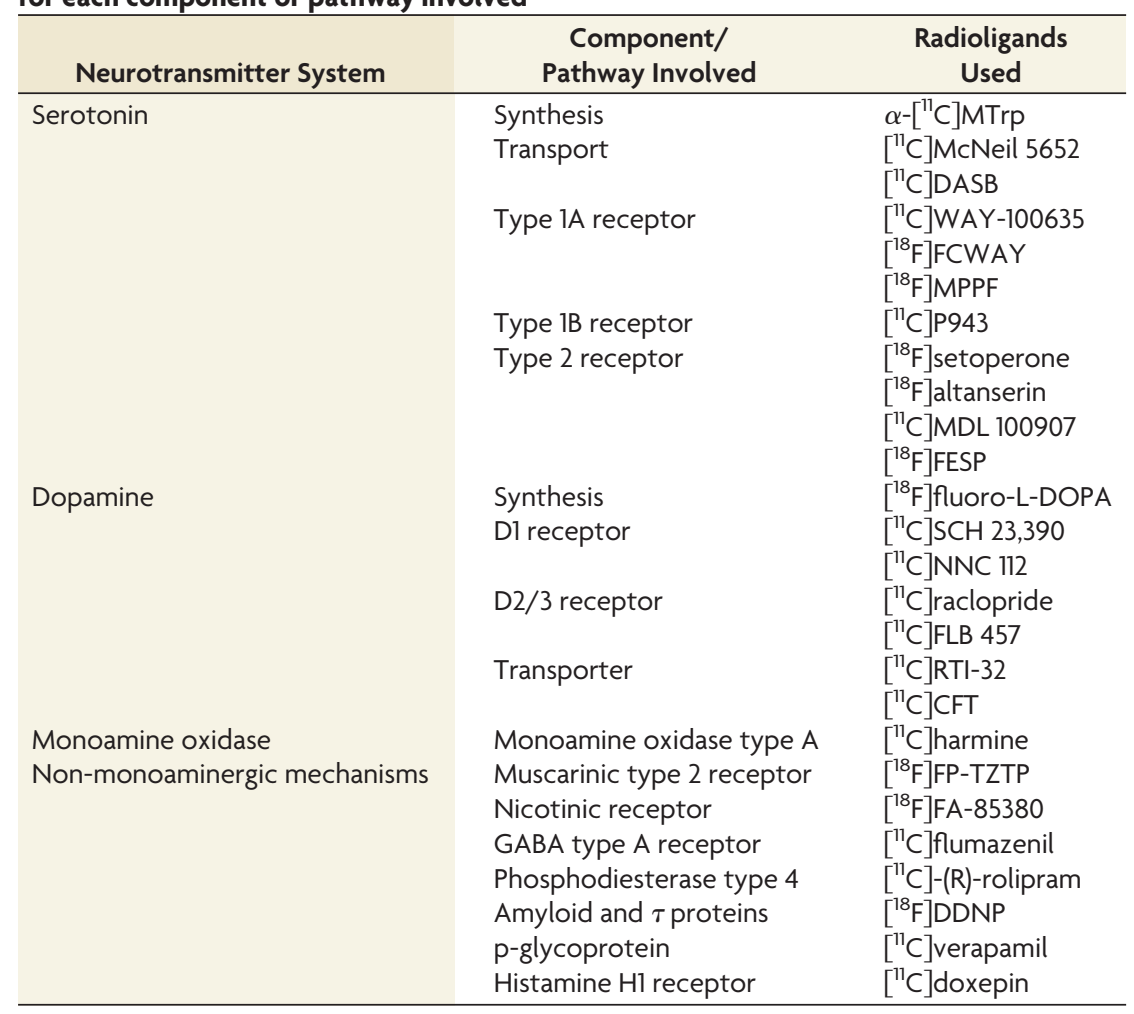

and place of radio-labeled molecules in the brain. The basic molecular tools for PET studies are typically synthetic compounds radio-labeled with positron-emitting nuclides, which enter the brain and bind to target macromolecules. The status of neuroreceptors is typically described in terms of the magnitude with which they bind the PET radioligand, expressed as binding potential or distribution volume. Hence PET estimates of receptor binding depend on a combination of 3 factors: 1) the number of neuroreceptors in a molecular conformation, 2) the affinity of neuroreceptors for the radioisotope, and 3) concentration of endogenous neurotransmitters near the neuroreceptors.

In seminal articles, Smith and Jakob$\operatorname{sen}^{72,73}$ and Savitz and Drevets ${ }^{74}$ offered comprehensive reviews of the research findings in the field to date for various radioligands, categorized by their target neurotransmitter systems, with serotonin type $1 \mathrm{~A}$ receptors being the most extensively studied. Table 3 provides an overview of the most common neurotransmitter systems studied with PET imaging and the radioligands that have been used to target each component or pathway. We hereby present a few key findings of these reviews and examine their implications.

In general, PET studies have produced differences between patients with depression and healthy controls across various radioligands and neurotransmitter systems, though contrary evidence has also been found. In serotonin transport, binding potentials are found to be lower in various brain regions of depressed patients with both unipolar or bipolar disorder for both radioligands $\left[{ }^{11} \mathrm{C}\right] \mathrm{McNeil}$ $5652^{75-77}$ and $\left[{ }^{11} \mathrm{C}\right] \mathrm{DASB},{ }^{78-81}$ though some studies were unable to find a reliable difference between depressed and healthy subjects ${ }^{82,83}$ for $\left[{ }^{11} \mathrm{C}\right] \mathrm{DASB}$. For the serotonin type $1 \mathrm{~A}$ receptor, for which most research has been done by using $\left[{ }^{11} \mathrm{C}\right]$ WAY-100635, most studies have found that the binding potential is reduced for patients with depression compared with healthy subjects, ${ }^{84-88}$ though some studies have found results in the converse direction, ${ }^{89,90}$ and a few others have found no difference between depressed and healthy subjects. ${ }^{91,92}$ However, none of the results were robust enough to be used for diagnostic purposes.

While other neurotransmitter systems have not been as extensively researched, the literature available also suggested a reduction in binding potentials for patients with depression compared with healthy subjects for the serotonin type 2 receptor by using $\left[{ }^{18} \mathrm{~F}\right]$ altanserin, ${ }^{93,94}$ dopamine synthesis by using $\left[{ }^{18} \mathrm{~F}\right]$ fluoro-L-DOPA, ${ }^{95}$ dopamine D1 receptor by using $\left[{ }^{11} \mathrm{C}\right] \mathrm{SCH} 23,390{ }^{96}$ and $\left[{ }^{11} \mathrm{C}\right] \mathrm{NNC} 112,{ }^{97}$ histamine $\mathrm{H} 1$ receptor by using $\left[{ }^{11} \mathrm{C}\right]$ doxepin, ${ }^{98}$ and phosphodiesterase type 4 by by using $\left[{ }^{11} \mathrm{C}\right](\mathrm{R})$-rolipram. ${ }^{99}$ Conflicting findings have emerged for dopamine $\mathrm{D} 2 / 3$ receptors by using $\left[{ }^{11} \mathrm{C}\right]$ raclopride, with Meyer et 
$\mathrm{al}^{100}$ finding elevated binding potentials for patients with depression compared with healthy controls and Montgomery et al ${ }^{101}$ finding the converse. For monoamine oxidase type A, elevated levels of binding potential have been found for patients with depression compared with healthy subjects by using $\left[{ }^{11} \mathrm{C}\right]$ harmine. ${ }^{102,103}$

Despite detecting group differences between depressed and healthy subjects, most studies have unfortunately failed to find any correlation between binding potentials and depression severity or clinical conditions across various radioligands and neurotransmitter systems. This failure to find a correlation surfaced for serotonin synthesis by using $\alpha-\left[{ }^{11} \mathrm{C}\right] \mathrm{MTrp}{ }^{104}$; serotonin transport by using $\left[{ }^{11} \mathrm{C}\right] \mathrm{McNeil} 5652^{75,76}$; serotonin type $1 \mathrm{~A}$ receptor by using $\left[{ }^{11} \mathrm{C}\right] \mathrm{WAY}-100635^{87,88,90,91,105}$; serotonin type 2 receptor by using $\left[{ }^{18} \mathrm{~F}\right]$ setoperone, ${ }^{106}\left[{ }^{18} \mathrm{~F}\right]$ altanserin, ${ }^{93,94}$ and $\left[{ }^{11} \mathrm{C}\right]$ MDL $100907^{107}$; D1 receptor by using $\left[{ }^{11} \mathrm{C}\right] \mathrm{NNC} 112^{97}$; and $\mathrm{D} 2 / 3$ receptor by using $\left[{ }^{11} \mathrm{C}\right]$ raclopride. ${ }^{100,101}$

Similarly, studies that have examined the effects of antidepressant or electroconvulsive treatment have likewise failed to find a correlation between binding potentials and depression scores when comparing pre- and posttreatment outcomes. For example, in investigating monoamine oxidase type A, Meyer et $\mathrm{al}^{103}$ found that the beneficial clinical effects of antidepressant treatment failed to reliably affect regional binding of $\left[{ }^{11} \mathrm{C}\right]$ harmine in the brain. In investigating the effects of electroconvulsive therapy, no correlation was found between binding potentials and treatment effects for serotonin type $1 \mathrm{~A}$ receptor by using $\left[{ }^{11} \mathrm{C}\right] \mathrm{WAY}-100635,{ }^{85,107}$ for serotonin type 2 receptor by using $\left[{ }^{18} \mathrm{~F}\right]$ setoperone, ${ }^{108}$ and for $\mathrm{D} 2 / 3$ receptor by using $\left[{ }^{11} \mathrm{C}\right] \mathrm{FLB} 457,{ }^{109}$ despite clinical improvement in most or all patients. This may limit the utility of PET imaging for assessing the clinical efficacy of medications.

Nevertheless, PET imaging may offer some promise in distinguishing responders and nonresponders to treatment. For example, Moses-Kolko et $\mathrm{al}^{110}$ found that binding of $\left[{ }^{11} \mathrm{C}\right]$ WAY-100635 for serotonin type $1 \mathrm{~A}$ receptors in the orbital cortex was higher before treatment in nonresponders compared with responders. Miller et $\mathrm{al}^{111}$ also found that accumulation of $\left[{ }^{11} \mathrm{C}\right] \mathrm{McNeil} 5652$ for serotonin transporters was reduced in patients who failed to show remission after 1 year of treatment compared with healthy subjects, in contrast to those who remitted. Again, the findings are not robust enough for clinical use. More research, however, is needed in this area before more definitive conclusions can be drawn.

Another promising area in which PET imaging may be used is in examining the effects of psychotherapeutic treatment approaches as opposed to medication. In a seminal study by Karlsson et al, ${ }^{112}$ the pre- and posttreatment binding potentials of $\left[{ }^{11} \mathrm{C}\right]$ WAY-100635 for serotonin type $1 \mathrm{~A}$ receptor were compared for patients who underwent psychodynamic therapy and those who received antidepressants. Surprisingly, it was found that only the former group had increased binding potential post-treatment, despite similar improvement in clinical outcomes in both groups. These findings may suggest that changes in binding potential could be related to changes in depressive cognition, as opposed to the current depressive affect as reflected by depression scores. In potential support of this finding, Meyer et $\mathrm{al}^{113}$ found correlations between the binding potential of $\left[{ }^{18} \mathrm{~F}\right]$ setoperone for serotonin type 2 receptor and the level of dysfunctional attitudes, as well as between the binding potential of $\left[{ }^{11} \mathrm{C}\right] \mathrm{DASB}$ and the magnitude of negative thinking ${ }^{82}$ in separate studies, even though binding potentials were not correlated with depression scores in the former and were related to current depressive episodes in the latter.
Some researchers have also explored the use of PET imaging in looking for potential differences between patients with depression who have recovered and healthy subjects, with the aim of examining whether depression involves persistent underlying molecular abnormalities and whether recurrence of illness may be predicted by PET. Findings, however, have been limited and mixed. For example, Bhagwagar et $\mathrm{al}^{114}$ found no difference in binding potential between recovered patients and healthy subjects for serotonin transporter by using $\left[{ }^{11} \mathrm{C}\right] \mathrm{DASB}$. In addition, while Bhagwagar et $\mathrm{al}^{105}$ found that recovered patients had lower binding potentials of $\left[{ }^{11} \mathrm{C}\right]$ WAY-100635 for serotonin type $1 \mathrm{~A}$ receptor compared with healthy subjects, Miller et $\mathrm{al}^{89}$ found that binding potentials were increased for the same radioligand for both remitted and currently subjects with depression compared with healthy subjects. Estimates of binding potential for the latter study, however, depended heavily on the region used as reference tissue, with cerebellar white matter giving higher values for binding potentials in remitted patients compared with healthy subjects and cerebellar gray matter producing results in the converse direction. In investigating serotonin type 2 receptor, Bhagwagar et $\mathrm{al}^{107}$ found that recovered depressed patients had higher binding potentials of $\left[{ }^{11} \mathrm{C}\right] \mathrm{MDL} 100907$ in various brain regions compared with healthy subjects; for monoamine oxidase type A, binding potentials were similarly elevated for $\left[{ }^{11} \mathrm{C}\right]$ harmine in brain regions of both currently depressed and recovered depressed subjects compared with never-depressed subjects, with recurrence of depression associated with elevated binding. ${ }^{103}$ To our knowledge, no longitudinal studies have yet been conducted to explore the utility of PET imaging for predicting the recurrence of depression in recovered patients; this may be a promising area for future research.

Given the growing interest in GABA, Klumpers et $\mathrm{al}^{115}$ showed that bilateral reduction in limbic parahippocampal and right temporal $\left[{ }^{11} \mathrm{C}\right]$ flumazenil binding found in MDD indicates decreased GABA(A)-benzodiazepine receptor complex affinity and/or number. The inverse relationship between GABA(A) binding in the temporal lobe and hypothalamus-pituitary axis activity suggests that hypothalamus-pituitary axis hyperactivity is partly due to reduced GABAergic inhibition. However, this study was based only on 11 subjects with depression and 9 controls and awaits further replication.

\section{DISCUSSION}

Molecular imaging was envisaged to explain and explore the neuromolecular basis of depressive disorders, to study pharmacologic agents, and assess treatment outcomes. In general, the monoamines are studied by using PET, and small molecules are studied by using MR spectroscopy. Despite rapid advances in imaging technology and new radio-labeled compounds and a series of published studies, molecular imaging for MDD is still very much a work in progress.

The findings thus far can be briefly summarized. For MR spectroscopy, the common metabolites studied are NAA, Glx, GABA, Cho, and mIns. Presently, findings for Glx and GABA appear to be the most promising, with most studies finding a decrease in Glx and GABA levels in brain regions of patients with depression relative to healthy controls, which increase in response to treatment. Nevertheless, contrary results have been found. No significant differences have generally been found between depressed and healthy subjects for NAA or NAA/Cr and mIns, though conflict- 
ing findings exist, and evidence is mixed for Cho. Despite the limitations in MR spectroscopy studies, Caverzasi et $\mathrm{al}^{55}$ opined that MR spectroscopy has good potential for enhancing the understanding of the mechanisms underlying MDD treatments and for helping in evaluating treatment efficacy.

For PET, comparison studies between subjects with depression and healthy controls have been shown for several radiolabeled compounds. A few studies have found differences in binding potentials for medication-naïve patients relative to healthy subjects or remitted, depressive patients treated with medication. These results provide some reassurance of the validity of the monoamine hypothesis in depression. However, several studies have failed to find a correlation between binding potential and depression severity or other clinical variables. Moreover, there is no correlation between the beneficial effects of potent antidepressant treatment and PET binding. This severely limits the utility of PET to study pharmacologic effects and treatment outcomes. If this means that the molecular systems probed by current PET ligands are stable, then the discovery of new radioactive ligands along with new scanning protocols will be needed.

The clinical utility of PET is also currently limited. While PET imaging may show differences in depressed-versus-healthy subjects, it is unlikely to be used for diagnostic purposes for the following reasons: First, as mentioned above, the preponderance of evidence has shown that PET imaging is not correlated with depression severity and other clinical variables. Second, although the bulk of studies have found differences between depressed and healthy subjects, all of these differences have been found post hoc and there is, to our knowledge, no study that has examined the specificity and sensitivity of using PET as a potential diagnostic tool. Moreover, the ethical issues involved in injecting a potentially hazardous radioactive substance into patients may preclude its widespread use in clinical diagnosis. There is, nevertheless, some promise in using PET imaging to distinguish between responders and nonresponders to treatment, which may give us more insight into why a certain population responds to certain medications and thus whether certain medications are more suitable for certain populations. In addition, most studies in PET imaging in depression have been performed on serotonergic neurotransmissions, and more research may be needed for dopaminergic, monoamine oxidase, and catecholaminergic transmissions.

Few comparisons can be drawn between the findings of MR spectroscopy and PET because MR spectroscopy and PET have generally been used to examine different compounds. A common compound studied by both, however, is GABA, in which a putative role in the pathophysiology of depression has recently been postulated. Preliminary evidence from both modalities has suggested decreased levels of GABA in subjects with MDD compared with controls, albeit in different brain regions. Decreases in GABA have mainly been reported in the occipital cortex by using MR spectroscopy, while PET found a reduction mainly in the limbic parahippocampal and temporal areas. However, to our knowledge, only a single study has been conducted on GABA with PET on a small sample. Although more studies have been performed using MR spectroscopy on GABA, definitive conclusions about the role of GABA in depression await further research and replication.
If one compared the 2 modalities, a distinct advantage of MR spectroscopy over PET is that MR spectroscopy is noninvasive and requires neither radioactive ligands nor ionizing radiation. On the other hand, MR spectroscopy is, by its very nature, restricted to the study of small metabolites and cannot be used to examine larger compounds that are of most interest in depression, such as serotonin and dopamine.

\section{Limitations and Future Directions}

The current state of research in MR spectroscopy and PET imaging shares similar limitations. First, studies for both modalities are generally small, and few are replicated. Second, methodologies of implementation and analysis vary widely across different studies for both modalities, and this variation may contribute to the production of confusing and conflicting results. Uniform or standardized protocols should be established to allow better comparison of studies

Last, one of the major challenges for both modalities is that depression is a clinical diagnosis that has no definitive neurobiologic correlates. It is inherently heterogeneous and multifactorial, involving an array of genetic factors, environmental input, and possible epigenetic interactions, and it involves multiple regions and domains in the brain. Because MR spectroscopy and PET are limited to only examining a single metabolite or radioligand at any single time, respectively, they may be capable only of offering microwindows into the workings of the disorder and may be unable to provide insight into the multitude of interactions that surely underlie the complex nature of the disorder.

In the future, studies involving other technologies (eg, fMRI and tractography) can complement these molecular imaging studies to perhaps provide a more nuanced and comprehensive characterization of the disorder. In addition, while numerous studies have provided evidence for the role of oxidative stress in depression, no researchers have yet used molecular imaging to examine metabolite levels in patients with depression. To our knowledge, only a single study ${ }^{116}$ has used proton MR spectroscopy to examine, in vivo, glutathione levels in young people with bipolar disorder, and it found no significant correlations between glutathione (an antioxidant) and clinical scores of depression or mania. The use of molecular imaging for exploring the role of oxidative stress in depression is worth further research.

Disclosures: K. Ranga R. Krishnan-UNRELATED: Patents (planned, pending or issued): brain-computer interface, ${ }^{*}$ Comments: not related to imaging or depression, licensed to Atentiv, Stock/Stock Options: Orexigen, Comments: not in this area or in imaging but in obesity. *Money paid to the institution.

\section{REFERENCES}

1. Mankoff DA. A definition of molecular imaging. J Nucl Med 2007; $48: 18 \mathrm{~N}, 21 \mathrm{~N}$

2. Weissleder R, Mahmood U. Molecular imaging. Radiology 2001; 219:316-33

3. Kang JH, Chung JK. Molecular-genetic imaging based on reporter gene expression. J Nucl Med 2008;49:164S-179S

4. Kessler RC, Berglund P, Demler O, et al. The epidemiology of major depressive disorder: results from the National Comorbidity Survey Replication (NCS-R). JAMA 2003;289:3095-105

5. American Psychiatric Association. Diagnostic and Statistical Manual of Mental Disorders. 5th ed. Arlington, Virginia: American Psychiatric Association; 2013 
6. American Psychiatric Association. Diagnostic and Statistical Manual of Mental Disorders. 4th ed. Arlington, Virginia: American Psychiatric Association; 2000

7. Duman RS. Molecular and cellular pathogenesis of depression and mechanisms for treatment response. In: Charney DS, Sklar P, Buxbaum JD, et al, eds. Neurobiology of Mental Illness. 4th ed. New York: Oxford University Press; 2013:425-37

8. Charney DS. Monoamine dysfunction and the pathophysiology and treatment of depression. J Clin Psychiatry 1998;59(suppl 14):11-14

9. Heninger GR, Delgado PL, Charney DS. The revised monoamine theory of depression: a modulatory role for monoamines, based on new findings from monoamines, based on new findings from monoamine depletion experiments in humans. Pharmacopsychiatry 1996;29:2-11

10. Jacobsen JP, Medvedev IO, Caron MG. The 5-HT deficiency theory of depression: perspectives from a naturalistic 5-HT deficiency model, the tryptophan hydroxylase 2Arg439His knockin mouse. Philos Trans R Soc Lond B Biol Sci 2012;367:2444-59

11. Pariante CM, Nemeroff CB. Unipolar depression. In: Schlaepfer TE, Nemeroff CB, eds. Handbook of Clinical Neurology: Neurobiology of Psychiatric Disorders. Amsterdam, the Netherlands: Elsevier; 2012:239-49

12. Brambilla P, Perez J, Barale F, et al. GABAergic dysfunction in mood disorders. Mol Psychiatry 2003;8:721-37, 715

13. Petty F. Plasma concentrations of gamma-aminobutyric acid (GABA) and mood disorders: a blood test for manic depressive disease. Clin Chem 1994;40:296-302

14. Sanacora G, Mason GF, Rothman DL, et al. Increased occipital cortex GABA concentrations in depressed patients after therapy with selective serotonin reuptake inhibitors. Am J Psychiatry 2002;159:663-65

15. Möhler H. The GABA system in anxiety and depression and its therapeutic potential. Neuropharmacology 2012;62:42-53

16. Maciag D, Hughes J, O'Dwyer G, et al. Reduced density of calbindin immuno-reactive GABAergic neurons in the occipital cortex in major depression: relevance to neuroimaging studies. Biol Psychiatry 2010;67:465-70

17. Karolewicz B, Maciag D, O’Dwyer G, et al. Reduced level of glutamic acid decarboxylase- $67 \mathrm{kDa}$ in the prefrontal cortex in major depression. Int J Neuropsychopharmacol 2010;13:411-20

18. Serafini G, Pompili M, Innamorati M, et al. Pharmacological properties of glutamatergic drugs targeting NMDA receptors and their application in major depression. Curr Pharm Des 2013;19:1898-922

19. Pfleiderer B, Michael N, Erfurth A, et al. Effective electroconvulsive therapy reverses glutamate/glutamine deficit in the left anterior cingulum of unipolar depressed patients. Psychiatry Res 2003;122:185-92

20. Petrie RXA, Reid IC, Stewart CA. The N-methyl-D-aspartate receptor, synaptic plasticity, and depressive disorder: a critical review. Pharmacol Ther 2000;87:11-25

21. Agarwal N, Port JD, Bazzocchi M, et al. Update on the use of MR for assessment and diagnosis of psychiatric diseases. Radiology 2010;255:23-41

22. $\mathrm{Ng} \mathrm{F}$, Berk $\mathrm{M}$, Dean $\mathrm{O}$, et al. Oxidative stress in psychiatric disorders: evidence base and therapeutic implications. Int J Neuropsychopharmacol 2008;11:851-76

23. Siwek M, Sowa-Kucma M, Dudek D, et al. Oxidative stress markers in affective disorders. Pharmacol Rep 2013;65:1558-71

24. Palta P, Samuel LJ, Miller ER, et al. Depression and oxidative stress: results from a meta-analysis of observational studies. Psychosom Med 2014;76:12-19

25. Yanik M, Erel O, Kati M. The relationship between potency of oxidative stress and severity of depression. Acta Neuropsychiatr 2004; 16:200-03

26. Chung CP, Schmidt D, Stein CM, et al. Increased oxidative stress in patients with depression and its relationship to treatment. Psychiatry Res 2013;206:213-16

27. Michel TM, Frangou S, Thiemeyer D, et al. Evidence for oxidative stress in the frontal cortex in patients with recurrent depressive disorder: a postmortem study. Psychiatry Res 2007;151:145-50

28. Kotan VO, Sarandol E, Kirhan E, et al. Effects of long-term antidepressant treatment on oxidative status in major depressive disorder: a 24-week follow-up study. Prog Neuropsychopharmacol Biol Psychiatry 2011;35:1284-90

29. Sarandol A, Sarandol E, Eker SS, et al. Major depressive disorder is accompanied with oxidative stress: short-term antidepressant treatment does not alter oxidative-antioxidative systems. Hum Psychopharmacol 2007;22:67-73

30. Drevets WC, Price JL, Simpson JR Jr, et al. Subgenual prefrontal cortex abnormalities in mood disorders. Nature 1997;386:824-27

31. Beyer JL, Krishnan KR. Volumetric brain imaging findings in mood disorders. Bipolar Disord 2002;4:89-104

32. Lee AL, Olge WO, Robert M. Stress and depression: possible links to neuron death in the hippocampus. Bipolar Disord 2002;4:117-28

33. Wang L, Hermens DF, Hickie IB, et al. A systematic review of resting-state functional-MRI studies in major depression. J Affect Disorders 2012;142:6-12

34. Payne GS, Leach MO. Applications of magnetic resonance spectroscopy in radiotherapy treatment planning. Br J Radiol 2006;(79 spec no 1):S16-26

35. van der Graaf M. In vivo magnetic resonance spectroscopy: basic methodology and clinical applications. Eur Biophys J 2010;39:527-40

36. Lu H, Yang Y, Liu P. Brain imaging methodologies. In: Charney DS, Sklar P, Buxbaum JD, Nestler EJ, eds. Neurobiology of Mental Illness. 4th ed. New York: Oxford University Press; 2013:199-211

37. Lyoo IK, Renshaw PF. Magnetic resonance spectroscopy: current and future applications in psychiatric research. Biol Psychiatry 2002;51:195-207

38. Moore CM, Renshaw PF. Magnetic resonance spectroscopy studies of affective disorders. In: Krishna KR, Doraiswamy PM, eds. Brain Imaging in Clinical Psychiatry. New York: Marcel Decker; 1997:185-214

39. Bolo NR, Hodé Y, Nédélec JF, et al. Brain pharmacokinetics and tissue distribution in vivo of fluvoxamine and fluoxetine by fluorine magnetic resonance spectroscopy. Neuropsychopharmacology 2000;23:428-38

40. Miner CM, Davidson JRT, Potts NLS, et al. Brain fluoxetine measurements using fluorine magnetic resonance spectroscopy in patients with social phobia. Biol Psychiatry 1995;38:696-98

41. Strauss WL, Unis AS, Cowan C, et al. Fluorine magnetic resonance spectroscopy measurement of brain fluvoxamine and fluoxetine in pediatric patients treated for pervasive developmental disorders. Am J Psychiatry 2002;159:755-60

42. Wolters M, Mohades SG, Hackeng TM, et al. Clinical perspectives of hybrid proton-fluorine magnetic resonance imaging and spectroscopy. Invest Radiol 2013;48:341-50

43. Iosifescu DV, Renshaw PF. 31P-Magnetic resonance spectroscopy and thyroid hormones in major depressive disorder: toward a bioenergic mechanism in depression. Harv Rev Psychiatry 2003;11:51-63

44. Soares JC, Krishnan KR, Keshavan MS. Nuclear magnetic resonance spectroscopy: new insights into the pathophysiology of mood disorders. Depression 1996;4:14-30

45. Yildiz A, Sachs GS, Dorer DJ, et al. 31P nuclear magnetic resonance spectroscopy findings in bipolar illness: a meta-analysis. Psychiatry Res 2001;106:181-91

46. Volz HP, Rzanny R, Riehemann S, et al. 31P magnetic resonance spectroscopy in the frontal lobe of major depressed patients. Eur Arch Psychiatry Clin Neurosci 1998;248:289-95

47. Harper DG, Jensen JE, Ravichandran C, et al. Tissue-specific differences in brain phosphodiesters in late-life major depression. $\mathrm{Am} J$ Geriatr Psychiatry 2013 Jan 11. [Epub ahead of print] 
48. Rauch SL, Renshaw PF. Clinical neuroimaging in psychiatry. Harv Rev Psychiatry 1995;2:297-312

49. Kusumakar V, MacMaster FP, Gates L, et al. Left medial temporal cytosolic choline in early onset depression. Can J Psychiatry 2001;46:959-64

50. Yildiz-Yesiloglu A, Ankerst DP. Review of ${ }^{1} \mathrm{H}$ magnetic resonance spectroscopy findings in major depressive disorder: a meta-analysis. Psychiatry Res 2006;147:1-25

51. Griffin JL, Bollard M, Nicholson JK, et al. Spectral profiles of cultured neuronal and glial cells derived from HRMAS (1) HNMR spectroscopy. NMR Biomed 2002;15:375-84

52. Wolfson M, Bersudsky Y, Hertz E, et al. A model of inositol compartmentation in astrocytes based upon efflux kinetics and slow inositol depletion after uptake inhibition. Neurochem Res 2000;25:977-82

53. Frey R, Metzler D, Fischer P, et al. Myo-inositol in depressive and healthy subjects determined by frontal ${ }^{1} \mathrm{H}$-magnetic resonance spectroscopy at 1.5 Tesla. J Psychiatr Res 1998;32:411-20

54. Rao NP, Venkatasubramanian G, Gangadhar BN. Proton magnetic resonance spectroscopy in depression. Indian $J$ Psychiatry 2011;53:307-11

55. Caverzasi E, Pichiecchio A, Poloni GU, et al. Magnetic resonance spectroscopy in the evaluation of treatment efficacy in unipolar major depressive disorder: a review of the literature. Funct Neurol 2012;27:13-22

56. Auer DP, Putz B, Kraft E, et al. Reduced glutamate in the anterior cingulate cortex in depression: an in vivo proton magnetic resonance spectroscopy study. Biol Psychiatry 2000;47:305-13

57. Mirza Y, Tang J, Russell A, et al. Reduced anterior cingulate cortex glutamatergic concentrations in childhood major depression. J Am Acad Child Adolesc Psychiatry 2004;43:341-48

58. Michael N, Erfurth A, Ohrmann P, et al. Metabolic changes within the left dorsolateral prefrontal cortex occurring with electroconvulsive therapy in patients with treatment resistant unipolar depression. Psychol Med 2003;33:1277-84

59. Sanacora G, Gueorguieva R, Epperson CN, et al. Subtype-specific alterations of gamma-aminobutyric acid and glutamate in patients with major depression. Arch Gen Psychiatry 2004;61:705-13

60. Yüksel C, Öngür D. Magnetic resonance spectroscopy studies of glutamate-related abnormalities in mood disorders. Biol Psychiatry 2010;68:785-94

61. Sanacora G, Mason GF, Rothman DL, et al. Reduced cortical gamma-aminobutyric acid levels in depressed patients determined by proton magnetic resonance spectroscopy. Arch Gen Psychiatry 1999;56:1043-47

62. Hasler G, van der Veen JW, Tumonis T, et al. Reduced prefrontal glutamate/glutamine and gamma-aminobutyric acid levels in major depression determined using proton magnetic resonance spectroscopy. Arch Gen Psychiatry 2007;64:193-200

63. Bhagwagar Z, Wylezinska M, Jezzard P, et al. Low GABA concentrations in occipital cortex and anterior cingulate cortex in medication-free, recovered depressed patients. Int J Neuropsychopharmacol 2008; 11:255-60

64. Mu J, Xie P, Yang ZS, et al. ${ }^{1} \mathrm{H}$ magnetic resonance spectroscopy study of thalamus in treatment resistant depressive patients. Neurosci Lett 2007;425:49-52

65. Vythilingam M, Charles HC, Tupler LA, et al. Focal and lateralized subcortical abnormalities in unipolar major depressive disorder: an automated multivoxel proton magnetic resonance spectroscopy study. Biol Psychiatry 2003;54:744-50

66. Delgado y Palacios RD, Campo A, Henningsen K, et al. Magnetic resonance imaging and spectroscopy reveal differential hippocampal changes in anhedonic and resilient subtypes of the chronic mild stress rat model. Biol Psychiatry 2011;70:449-57

67. Hemanth Kumar BS, Mishra SK, Rana P, et al. Neurodegenerative evidences during early onset of depression in CMS rats as detected by proton magnetic resonance spectroscopy at 7T. Behav Brain Res 2012;232:53-59
68. Xi G, Hui J, Zhang Z, et al. Learning and memory alterations are associated with hippocampal $\mathrm{N}$-acetylaspartate in a rat model of depression as measured by ${ }^{1}$ H-MRS. PLoS One 2011;6:e28686

69. Czéh B, Michaelis T, Watanabe T, et al. Stress-induced changes in cerebral metabolites, hippocampal volume, and cell proliferation are prevented by antidepressant treatment with tianeptine. Proc Natl Acad Sci U S A 2001;98:12796-801

70. Perrine SA, Ghoddoussi F, Michaels MS, et al. Ketamine reverses stress-induced depression-like behavior and increased GABA levels in the anterior cingulate: an $11.7 \mathrm{~T}^{1} \mathrm{H}$-MRS study in rats. Prog Neuropsychopharmacol Biol Psychiatry 2013 Nov 15. [Epub ahead of print]

71. Renshaw PF, Parow AM, Hirashima F, et al. Multinuclear magnetic resonance spectroscopy studies of brain purines in major depression. Am J Psychiatry 2001;158:2048-55

72. Smith DF, Jakobsen S. Molecular tools for assessing human depression by positron emission tomography. Eur Neuropsychopharmacol 2009; 19:611-28

73. Smith DF, Jakobsen S. Molecular neurobiology of depression: PET findings on the elusive correlation with symptom severity. Front Psychiatry 2013;4:8

74. Savitz JB, Drevets WC. Neuroreceptor imaging in depression. Neurobiol Dis 2013;52:49-65

75. Oquendo MA, Hastings RS, Huang YY, et al. Brain serotonin transporter binding in depressed patients with bipolar disorder using positron emission tomography. Arch Gen Psychiatry 2007;64:201-08

76. Parsey RV, Hastings RS, Oquendo MA, et al. Lower serotonin transporter binding potential in the human brain during major depressive episodes. Am J Psychiatry 2006;163:52-58

77. Reivich M, Amsterdam JD, Brunswick DJ, et al. PET brain imaging with $\left[{ }^{11} \mathrm{C}\right](+) \mathrm{McN} 5652$ shows increased serotonin transporter availability in major depression. J Affect Disord 2004;82:321-27

78. Reimold M, Knobel A, Rapp MA, et al. Central serotonin transporter levels are associated with stress hormone response and anxiety. Psychopharmacology (Berl) 2011;213:563-72

79. Reimold M, Batra A, Knobel A, et al. Anxiety is associated with reduced central serotonin transporter availability in unmedicated patients with unipolar major depression: a [11C]DASB PET study. Mol Psychiatry 2008;13:606-13, 55

80. Cannon DM, Ichise M, Rollis D, et al. Elevated serotonin transporter binding in major depressive disorder assessed using positron emission tomography and [11C]DASB; comparison with bipolar disorder. Biol Psychiatry 2007;62:870-77

81. Cannon DM, Carson RE, Nugent AC, et al. Reduced muscarinic type 2 receptor binding in subjects with bipolar disorder. Arch Gen Psychiatry 2006;63:741-47

82. Meyer JH, Houle S, Sagrati S, et al. Brain serotonin transporter binding potential measured with carbon 11-labeled DASB positron emission tomography: effects of major depressive episodes and severity of dysfunctional attitudes. Arch Gen Psychiatry 2004; 61:1271-79

83. Meyer JH, Wilson AA, Sagrati S, et al. Serotonin transporter occupancy of five selective serotonin reuptake inhibitors at different doses: an [11C]DASB positron emission tomography study. Am J Psychiatry 2004;161:826-35

84. Parsey RV, Ogden RT, Miller JM, et al. Higher serotonin 1A binding in a second major depression cohort: modeling and reference region considerations. Biol Psychiatry 2010;68:170-78

85. Saijo T, Takano A, Suhara T, et al. Effect of electroconvulsive therapy on 5-HT1A receptor binding in patients with depression: a PET study with [11C]WAY 100635. Int J Neuropsychopharmacol 2010;13:785-91

86. Meltzer CC, Price JC, Mathis CA, et al. Serotonin 1A receptor binding and treatment response in late-life depression. Neuropsychopharmacology 2004;29:2258-65

87. Hirvonen J, Karlsson H, Kajander J, et al. Decreased brain serotonin 5-HT1A receptor availability in medication-naïve patients 
with major depressive disorder: an in-vivo imaging study using PET and [carbonyl-11C]WAY-100635. Int J Neuropsychopharmacol 2008;11:465-76

88. Drevets WC, Thase ME, Moses-Kolko EL, et al. Serotonin-1A receptor imaging in recurrent depression: replication and literature review. Nucl Med Biol 2007;34:865-77

89. Miller JM, Brennan KG, Ogden TR, et al. Elevated serotonin 1A binding in remitted major depressive disorder: evidence for a trait biological abnormality. Neuropsychopharmacology 2009;34:2275-84

90. Sullivan GM, Ogden RT, Oquendo MA, et al. Positron emission tomography quantification of serotonin-1A receptor binding in medication-free bipolar depression. Biol Psychiatry 2009;66: 223-30

91. Parsey RV, Oquendo MA, Ogden RT, et al. Altered serotonin 1A binding in major depression: a [carbonyl-C-11]WAY100635 positron emission tomography study. Biol Psychiatry 2006;59:106-13

92. Mickey BJ, Ducci F, Hodgkinson CA, et al. Monoamine oxidase A genotype predicts human serotonin $1 \mathrm{~A}$ receptor availability in vivo. J Neurosci 2008;28:11354-59

93. Mintun MA, Sheline YI, Moerlein SM, et al. Decreased hippocampal 5-HT2A receptor binding in major depressive disorder: in vivo measurement with $[18 \mathrm{~F}]$ altanserin positron emission tomography. Biol Psychiatry 2004;55:217-24

94. Sheline YI, Mintun MA, Moerlein SM, et al. Greater loss of 5-HT(2A) receptors in midlife than in late life. Am J Psychiatry 2002;159:430-35

95. Bragulat V, Paillere-Martinot ML, Artiges E, et al. Dopaminergic function in depressed patients with affective flattening or with impulsivity: [18F] fluoro-L-dopa positron emission tomography study with voxel-based analysis. Psychiatry Res 2007;154:115-24

96. Dougherty DD, Bonab AA, Ottowitz WE, et al. Decreased striatal D1 binding as measured using PET and [11C]SCH 23,390 in patients with major depression with anger attacks. Depress Anxiety 2006;23:175-77

97. Cannon DM, Klaver JM, Peck SA, et al. Dopamine type-1 receptor binding in major depressive disorder assessed using positron emission tomography and [(11)C]NNC-112. Neuropsychopharmacology 2009;34:1277-87

98. Kano M, Fukudo S, Tashiro A, et al. Decreased histamine H1 receptor binding in the brain of depressed patients. Eur J Neurosci 2004;20:803-10

99. Fujita M, Hines CS, Zoghbi SS, et al. Downregulation of brain phosphodiesterase type IV measured with (11)C-(R)-rolipram positron emission tomography in major depressive disorder. Biol Psychiatry 2012;72:548-54

100. Meyer JH, Ginovart N, Boovariwala A, et al. Elevated putamen D(2) receptor binding potential in major depression with motor retardation: an [11C]raclopride positron emission tomography study. Am J Psychiatry 2006;163:1594-602

101. Montgomery AJ, Stokes P, Kitamura Y, et al. Extrastriatal D2 and striatal D2 receptors in depressive illness: pilot PET studies using [11C]FLB 457 and [11C]raclopride. J Affect Disord 2007;101: $113-22$

102. Meyer JH, Ginovart N, Boovariwala A, et al. Elevated monoamine oxidase A levels in the brain: an explanation for the monoamine imbalance of major depression. Arch Gen Psychiatry 2006; 63:1209-16
103. Meyer JH, Wilson AA, Sagrati S, et al. Brain monoamine oxidase A binding in major depressive disorder: relationship to selective serotonin reuptake inhibitor treatment, recovery, and recurrence. Arch Gen Psychiatry 2009;66:1304-12

104. Rosa-Neto P, Diksic M, Okazawa H, et al. Measurement of brain regional alpha-[11C]methyl-L-tryptophan trapping as a measure of serotonin synthesis in medication-free patients with major depression. Arch Gen Psychiatry 2004;61:556-63

105. Bhagwagar Z, Rabiner EA, Sargent PA, et al. Persistent reduction in brain serotonin $1 \mathrm{~A}$ receptor binding in recovered depressed men measured by positron emission tomography with [11C]WAY100635. Biol Psychiatry 2004;9:386-92

106. Yatham LN, Liddle PF, Lam RW, et al. Effect of electroconvulsive therapy on brain 5-HT(2) receptors in major depression. Br J Psychiatry 2010;196:474-79

107. Bhagwagar Z, Hinz R, Taylor M, et al. Increased 5-HT(2A) receptor binding in euthymic, medication-free patients recovered from depression: a positron emission study with [11C]MDL 100,907. Am J Psychiatry 2006;163:1580-87

108. Lanzenberger R, Baldinger $P$, Hahn A, et al. Global decrease of serotonin-1A receptor binding after electroconvulsive therapy in major depression measured by PET. Mol Psychiatry 2013; 18:93-100

109. Saijo T, Takano A, Suhara T, et al. Electroconvulsive therapy decreases dopamine $D(2)$ receptor binding in the anterior cingulate in patients with depression: a controlled study using positron emission tomography with radioligand [11C]FLB 457. J Clin Psychiatry 2010;71:793-99

110. Moses-Kolko EL, Price JC, Thase ME, et al. Measurement of 5-HT1A receptor binding in depressed adults before and after anti-depressant drug treatment using positron emission tomography and [11C]WAY-100635. Synapse 2007;61:523-30

111. Miller JM, Oquendo MA, Ogden RT, et al. Serotonin transporter binding as a possible predictor of one-year remission in major depressive disorder. J Psychiatr Res 2008;42:1137-44

112. Karlsson H, Hirvonen J, Kajander J, et al. Research letter: psychotherapy increases brain serotonin 5-HT1A receptors in patients with major depressive disorder. Psychol Med 2010;40:523-28

113. Meyer JH, McMain S, Kennedy SH, et al. Dysfunctional attitudes and 5-HT2 receptors during depression and self-harm. Am J Psychiatry 2003;160:90-99

114. Bhagwagar Z, Murthy N, Selvaraj S, et al. 5-HTT binding in recovered depressed patients and healthy volunteers: a positron emission tomography study with [11C]DASB. Am J Psychiatry 2007;164:1858-65

115. Klumpers UM, Veltman DJ, Drent ML, et al. Reduced parahippocampal and lateral temporal GABAA-[11C]flumazenil binding in major depression: preliminary results. Eur J Nucl Med Mol Imaging 2010;37:565-74

116. Lagopoulos J, Hermens DF, Tobias-Webb J, et al. In vivo glutathione levels in young persons with bipolar disorder: a magnetic resonance spectroscopy study. J Psychiatr Res 2013;47:412-17

117. Narayana PA, Johnston D, Flamig DP. In vivo proton magnetic resonance spectroscopy studies of human brain. Magn Reson Imaging 1991;9:303-08 